\title{
FORMAS DE
}

INTERCULTURALIDAD

EN EL ARTE:

HIBRIDACIÓN Y

TRANSCULTURACIÓN

\section{Álvaro Villalobos-Herrera} Cynthia Ortega-Salgado

\begin{abstract}
Resumen
Este artículo considera que la hibridación y la transculturación son parte de la interculturalidad, ya que ambos responden a encuentros y choques entre grupos. Dichos procesos han sido abordados en diferentes ocasiones para mostrar sus influencias en las ciencias sociales y las humanidades. A partir de ello, se establecen sus diferencias en la producción artística como una manifestación de relaciones interculturales en las que se reflejan valores que denotan cambios y movilidades formales y conceptuales en la obra y pensamiento de sus autores. Se enfatiza el carácter procesual y de continua transformación en la que se produce el arte, como una forma de conocimiento; cuando una de sus características es la capacidad para establecer dispositivos entre forma y concepto que surgen de mezclas aleatorias y azarosas, obteniendo resultados móviles e imprecisos pero útiles y verificables con la misma validez que en las ciencias duras.
\end{abstract}

Palabras clave: interculturalidad, hibridación, transculturación, arte.

\section{Abstract}

The present article considers that concepts of hybridization and transculturation are embodied in the form of interculturality, due to both respond to encounters and confrontations between social groups, these processes have been studied on several occasions to realize their influence in social sciences and humanities. On this basis, this text establishes their 
differences in the artistic production as an intercultural expression in which certain values and qualities such as change and mobility are implicit in the work and thought of their authors. Moreover, characteristics of contemporary art are the process as an important form of knowledge and the ability to join shape and thought in art from previous, undetermined and uncertain mixtures to achieve useful and verifiable results commonly used in science.

Key words: interculturality, hybridization, transculturation, art.

\section{PROCESOS DE HIBRIDACIÓN}

Los procesos surgidos por las relaciones entre las culturas denominados como hibridación y transculturación están ganando terreno en la actualidad en el campo de las investigaciones en las ciencias las sociales, las humanidades y las artes. La hibridación en las artes visuales por ejemplo, corresponde a una definición usada para denominar cruces, mezclas e intersecciones que producen resultados con logros verificables en las disposiciones formales, contextuales y conceptuales de las obras. Uno de los autores contemporáneos más influyentes en el estudio del fenómeno en el campo de las ciencias sociales, es el analista Néstor García Canclini, quien designa la hibridación como la combinación de estructuras y procesos que en la cultura existían de forma separada, y que juntos forman nuevas organizaciones, la mayor de las veces con prácticas y sentidos novedosos. Como lo hemos mencionado en anteriores investigaciones, la hibridación corresponde a un término derivado de la biología o más bien extrapolado de esa disciplina para señalar fenómenos en los que la promiscuidad de las especies genera nuevos productos.

No obstante el carácter de novedad de los resultados entre las posibles mezclas, la hibridación no es un fenómeno que se pueda aplicar a todas las especies, ya que en algunos apareamientos se comprometen infertilidades implícitas en el origen de los individuos involucrados. La definición de hibridación en la biología implica la producción de organismos estériles, aunque más fuertes ya que entran en juego entidades complejas, como las características individuales de los apareados. A pesar de que en la genética abundan los ejemplos de hibridaciones bondadosas con el fin de aprovechar lo sobresaliente de las especies; no todas las mezclas resultan efectivas. Mucho menos, si los efectos se trasladan a campos prácticos, porque los grupos sociales cuando entran en dinámicas de coparticipación en pleno uso de sus facultades establecen relaciones diversas, y generan procesos interculturales más complejos.

No se pueden homogeneizar todos los movimientos de naturaleza sociocultural de la misma manera como se hace en la biología para establecer relaciones la cruza entre individuos aunque las posibilidades de mezclas entre razas y gentes son ilimitadas, tampoco se puede esperar que el concepto sea capaz de abarcar fenómenos interculturales naturales; como el ejemplo podemos referirnos a las mescolanzas en las creencias religiosas, los cruces entre poblaciones o los pastiches derivados de los dogmas que promueven los partidos políticos, que crecen y se fomentan diariamente entre la población. Cuando comenzamos el proyecto de investigación sobre la aplicación de la hibridación en el arte encontramos limitado el fenómeno y a pesar de que lo vimos relacionado con casos generalizantes como el mestizaje, lo multiétnico, la transculturación y el sincretismo, además de encontrar fusiones del término con fenómenos de intervisualidad, liminalidad, intertextualidad, etc., no pudimos precisar la hibridación prácticamente en las obras de arte revisadas.

Néstor García Canclini presenta en su libro "Culturas hibridas estrategias para entrar y salir de la modernidad", argumentos basados en que las culturas latinoamericanas en su mezcla con las europeas, inmersas en la modernidad intelectual filosófica y artística, se enfrentaron a la promesa de la modernidad económica que no llegó nunca completa y ahí se formó la hibridación. Y que, en cada caso de las colonias europeas, la modernidad llegó a destiempo, como lo podemos ver en los diferentes países latinoamericanos en los que se generó la unión de lo tradicional premoderno, con las acciones modernas y hasta posmodernas, ocasionando verdaderos pastiches denominados hibridaciones, transformaciones formales y sincretismos. En el juego entre los poderes culturales que se encontraron en la colonia, se entremezcló continuamente, lo hegemónico con lo popular y lo culto con lo masivo, produciendo resultados híbridos con cruces de contornos que se vuelven borrosos, inestables y ciertamente embrollados.

No se puede pensar que al tratar de definir cualquier fenómeno intercultural se debe entrar en una visión general de la cultura como ya lo habíamos mencionado al hablar de transculturación en el libro de procesos culturales en el arte y el diseño contemporáneo publicado por los autores de este artículo en 2009. Mejor sería tener una visión amplia pero detallada de las relaciones 
que pueden establecerse entre las formas artísticas, con el fin de señalar las características particulares de los objetos de estudio, tratando de no dejar cabos sueltos en el momento de explicar las alianzas, ya que esto posibilita el entendimiento del fenómeno a través de lecturas abiertas y plurales.

Entendidos los señalamientos del libro, Culturas Híbridas, como ejemplo podemos citar un caso registrado en el norte de México, en la ciudad de Tijuana, frontera con Estados Unidos, localizada en un territorio en el que florecen las culturas híbridas denominadas por García, por estar en una zona, desterritorializada, donde la música, la gastronomía, las letras, los sonidos, los aromas, el lenguaje, la visualidad, se funden en la piel de los mexicanos y los estadounidenses; pero además, su demografía se enriquece con personas de todo el mundo que constantemente viven o llegan ahí, con el ánimo de cruzar la frontera, formando una especie de tatuaje de múltiples tintas y colores, impreso sobre una piel rugosa y afectada por la topografía agreste del lugar. Esta ciudad es un ejemplo de síntesis cultural, que elogia la unificación de todos los elementos inter y transculturales pero: ¿Cuáles son y cómo identificar los elementos que se desplazan de un lado a otro de las fronteras entre los dos países? Denominar sintéticamente a la población como una cultura híbrida, no toma en cuenta las diferencias abismales entre los sistemas culturales que conviven ahí, pero que no siempre se integran, de una manera suave, sino violenta y explosiva. Los contrastes, las diferencias sociales y las disparidades culturales entre los estratos de donde provienen los discursos, ofrecen lecturas también desiguales, de resistencia a los poderes hegemónicos pero ricas en significados, sugerentes de análisis, que involucren más profundamente los mismos fenómenos culturales que allí suceden.

Es de anotar que en este sentido la hibridación no fija su atención en las contradicciones que imposibilitan las mezclas, sino que únicamente celebra las alianzas azarosas, que tienden a aplanar las situaciones intermedias, surgidas por la interacción de los sujetos; por ejemplo, las relaciones generadas en las producciones artísticas locales que no son ajenas a los sistemas culturales, la mayoría de las veces tienden a presentarse como homogéneas, planas y lisas, sin mostrar las tensiones surgidas, las aristas y los en los intersticios que sugieren nuevas lecturas que a primera vista no se apreciaban, pero que, por medio de una superación dialéctica se puede conocer a un nuevo tipo de sujeto a través del reconocimiento de las diferencias, en su interacción con otros individuos, como lo argumenta John Beverly en su libro sobre la situación de los estudios culturales de 1996.
Esta idea de distinción a partir de la diferencias generadas por la mezcla e interacción de individuos de distinta clase se aplica al caso de los artesanos oaxaqueños que Néstor García en libro citado en los párrafos iniciales, presenta a partir de sus investigaciones en Teotitlán del Valle, Oaxaca, México, donde identifica a un descendiente de indígenas que habla fluidamente zapoteco, inglés y español; y que salta sin problemas entre las diversas prácticas culturales derivadas de los desplazamientos motivados por su oficio entre México y Estados Unidos, conservando sus rasgos culturales más notorios. El hombre ha logrado amalgamar lo culto y lo popular con resultados eficientes en el mercado en el que está inmerso, ya que sus tapices con imágenes de Paul Klee, Pablo Picasso y Joan Miró, están integrados al circuito cultural de exposiciones en el Estado de California, Estados Unidos (García, 1990:224). En este caso el autor celebra la fluidez con la que el artesano reestructura las alianzas entre lo tradicional y lo moderno, lo popular y lo culto, lo nacional con lo extranjero y lo hegemónico con lo subalterno. Hasta ese momento todo es armonioso, excepto que el artesano pudo tener cruces culturales forzados simplemente por una necesidad económica, con un país que constantemente lo segrega y lo trata en consideración a su origen racial, siendo él además, uno de los pocos casos en los que se logró el estatus artesano-artista en Estados Unidos, pero no en México.

Individuos como este, no representan la totalidad del colectivo de su comunidad sino que están envueltos en las contradicciones de ambos sistemas culturales en los que están inmersos México y Estados Unidos, el interno y el externo, de tal suerte que sus actividades no pueden ser vistas con homogeneidad pues tampoco son acogidas de la misma manera en los dos países mencionados, en igualdad de condiciones. En las ciencias sociales, estas disparidades, incoherencias y anomalías no son tomadas en cuenta por el concepto de hibridación, por ello la resistencia de algunos sectores para unificar en este término características de interacción entre actores sociales con muchas diferencias. Por otro lado se discute la pertinencia en esos casos de la denominación de los llamados géneros impuros, que la mayor de las veces no encuentra cabida dentro de los aparatos culturales, sino que son tan móviles que denotan espacios contestatarios, contraculturales y de contrarréplica hasta que son estabilizados por un poder mayor o hegemónico que los absorbe y los masifica. Todos ellos componen discursos vitales en la polifonía actual contra toda voz totalitaria.

Una de las características del arte contemporáneo es la capacidad para 
establecer dispositivos de conjunción de formas y conceptos en las obras a partir de mezclas aleatorias, indeterminadas y azarosas, con el fin de obtener resultados móviles e imprecisos pero verificables. Por su carácter indeterminado y azaroso se distingue el arte procesual como una forma de producir conocimiento no fijo, aleatorio, cambiante y a la deriva. El artista contemporáneo se distingue como sujeto creativo, inmerso en una serie de rasgos culturales ciertamente transgresores, tanto de las ideas artísticas como de su entorno y de su quehacer profesional, generando resultados abiertos y transformacionales, tanto en las ideas como en las formas artísticas. Los aportes formales y conceptuales que validan la noción de obra de arte contemporánea están sustentados en la mezcla de ideas o procedimientos para formar la unidad en la obra a partir de la gran diversidad de posibilidades de interconexión e interculturalidad con que puede trabajar el artista.

El artista como un sujeto creativo inmerso en el ámbito de la cultura en la actualidad debe ser capaz de construir lazos de comunicación con los diferentes actores sociales, cuestionando y contraponiéndose al individualismo que promueve la globalización a través de las redes de información y la emergencia mediática en la que se puede ver a un sujeto encerrado en la aparentemente infinita pero limitada gama de posibilidades que le ofrece la pantalla de la computadora personal, enfrascándolo en un sistema cerrado, endógeno y autocomplaciente. Ahí se pueden localizar el arte contemporáneo y sus formas móviles, procesuales y cambiantes. Atravesando diversas fases y posibilidades de creación, en el tránsito hacia la madurez de la obra artística, en un devenir selectivo en el que hay pérdidas, redescubrimientos e incorporaciones de elementos que toma de las culturas con las que se permea. Esa es una condición indispensable para la producción de la obra de arte en la actualidad. El artista contemporáneo hábil en sus concepciones, mezcla y realiza una selección de los elementos que le sirven de cada una de sus fuentes de constitución y de cada uno de los estilos que le llegan circunstancialmente; elige y decide qué quitar y qué dejar en la obra de arte, proponiendo un redescubrimiento conciliador de poderes artísticos e interculturales que confronten y nutran sus propios valores y capacidades en formas incorporadas a procesos de creación móviles y cambiantes.

Vale la pena repetir postulados que hemos utilizado en artículos publicados con anterioridad, que argumentan que las culturas en general y el arte como uno de los resultados palpables en los que se puede verificar formas de pensamiento y comportamiento cultural específico, se han visto afectadas por el mismo hecho trascendental del que han emergido toda suerte de fusiones a partir del flujo, migración y tránsito de pensamientos y de personas de un país a otro, de una nación a otra o simplemente de una región territorial a otra, poniendo en práctica la capacidad para borrar las fronteras geográficas, arrastrando consigo sus costumbres, sus modos de pensar y de sentir que repercuten en la forma de vida de la sociedad que los recibe y se reflejan típicamente en el comportamiento de grandes grupos, en las ideologías, los modos de sentir y de expresarse, de mezclarse y rechazarse, de aprehender el mundo, de recibir sus vibraciones sensoriales, en su integridad para percibirlas y manifestarlas, utilizando el poder del pensamiento y la comunicación en un sentido amplio de los conceptos antes explicados.

\section{PROCESOS DE TRANSCULTURACIÓN}

Lotranscultural en la historia reciente comienzaa registrarse con aproximación a las acciones colonizadoras europeas. Por ejemplo en América, con la llegada de Cristóbal Colón comenzó un proceso que sacudió definitivamente las prácticas de los pueblos indígenas, además en ese caso se convirtió en un efecto cultural recíproco en la medida que la mezcla de nativos con europeos y africanos generó todos los mestizajes posibles. Como resultados prácticos se pueden ver las aportaciones fundamentales de los negros africanos en la constitución de las culturas posteriores a las colonias. Como fuerza influyente son importantes sus vastísimas intervenciones en los valores de organización comunitaria, política y cosmogónica, por ejemplo la cocina se enriquece con la mezcla de productos y sabores, la música polirrítmica y polifónica es ejecutada con nuevos instrumentos; la danza con las diversas técnicas del cuerpo, la religión fue impactada con la polideidad y el animismo, así como la espiritualidad fue transformada en muchos sentidos por la fuerza de la moral. La medicina incluyó la herbolaria y las tradiciones orales afectaron las prácticas de la escritura y la difusión del conocimiento. Las fuerzas de trabajo se vieron reflejadas en las explotaciones ganaderas y en las plantaciones agrícolas de tabaco y azúcar especialmente, asimismo las estrategias militares cambiaron de proporción cuando incluyeron la participación de negros y mulatos en las guerras de independencia de los países caribeños.

Al respecto, en una investigación anterior citamos a Edouard Glissant que argumentó que los individuos de raza negra llegaron a América como 
"migrantes desnudos" (2002), lo que reconocimos como un término lleno de belleza y poesía, porque cuando el individuo en su desplazamiento no carga nada material que delate su pertenencia a un lugar específico, vive un drama que afianza las creencias y los sentimientos propios, fincados en el espíritu y en la memoria. En primera instancia la mezcla del europeo, el nativo americano y el negro fue la base de construcción de las culturas actuales y su peregrinar por el mundo ocasionó muchas relaciones entre sujetos y comunidades. Después de tantos años de relaciones han logrado trascender todas las fronteras, hasta las de la denominada en algunos ambientes intelectuales como, memoria colectiva, que, de modo inusitado, ha recreado ritos en torno a la sabiduría, la muerte y la vida de la colectividad latinoamericana, que en el ambiente eurocentrista y etnocentrista de la escritura han sido concebidas de manera fija.

Otro ejemplo de transculturación desde la antigüedad, lo podemos ver en la América del sur cuando la capital del imperio inca, fue invadida para ser colonizada por los españoles con el deseo de convertir a los indígenas al cristianismo como costumbre europea. La manera de plasmar el deseo de los europeos ejemplifica una eficaz transculturación del lugar en el que vivían los Incas. Transculturalizando los ritos que practicaban mediante el implante forzoso del Dios de la religión católica, por medio de nuevas ceremonias, inevitablemente produjo formas diversas de resistencia y sincretismos. La intención de los colonizadores españoles en ese caso, fue dar a los indios la oportunidad de parecerse a ellos, adoptando sus costumbres, pero de ningún modo concibiéndolos como a los europeos. El hecho práctico consistió en domesticar a los nativos para que recitaran el canon cultural europeo y actuaran bajo parámetros medibles y controlados. La fe de la comunidad con el tiempo se dejó doblegar y se mezcló con las formas de adoración cristianas en el caso de la religión, por lo que en festividades recientes, es común escuchar canciones antiguas con adaptaciones modernas; también podemos ver danzas actuales que presentan bailarines ataviados con trajes incas tradicionales antiguos.

El conjunto de prácticas nativas refrendadas por los colonizadores evolucionaron, mutaron y se desarrollaron de manera conjunta. Este hecho es importante en los procesos de transculturación, ya que cuando se conquista y se derrota a la vez, se muestra el sometimiento y la ocupación, pero también se puede verificar en torno a ese hecho, un proceso derivado de una falla en el propósito colonizador. Hay aquí una doble lectura, por un lado, se puede ver el fracaso del anfitrión colonizado que consiste en ver su pasado invadido y convertido en otra cosa, pero con una victoria evidente basada en la conservación de sus costumbres, que aunque resignificadas, se tratan de mantener firmes e infranqueables ante los cambios y mutaciones que de todos modos se dan aunque en la mayoría de los casos lentamente, gracias a la resistencia que oponen a los colonizadores.

En el desarrollo de la interculturalidad, la otredad tiene un espacio exclusivo, no para ser escuchada o entendida, sino para ser vista y contemplada con curiosidad y asombro. En la transculturación por ejemplo, la alteridad es el sustento del que el otro depende, de que sea aceptado y promovido, siempre y cuando esté controlado; en la transculturación el principio de alteridad consiste en el reconocimiento de la diferencia entre el yo, el otro y nosotros, en la convivencia del amigo y el enemigo, el yo que sabe de sí, a partir de la identidad otro.

El término transculturación apareció en el campo estético para designar a objetos de arte transferidos de un patrimonio cultural a otro. Un ejemplo se da en los escritos del etnólogo cubano Fernando Ortiz Fernández, estudioso de las leyes y la antropología criminal que pasó varias décadas estudiando este proceso cultural. En América se puede ver el efecto de la transculturación a partir de las mezclas entre blancos, negros e indígenas reflejado en sus éticas, sus pensamientos, sus formas de relacionarse y por supuesto en el arte. Desde la antigüedad a nuestros días, un permanente e ininterrumpido contacto entre las culturas hace que interactúen y se interrelacionen a través de los lenguajes, las músicas, los bailes y las religiones, sin pasar por alto el dolor sufrido por algunas comunidades al recibir las combinaciones, sobre todo para quienes sienten relegadas sus costumbres cuando tratan de integrarse con los colonizadores.

os ejemplos de Fernando Ortiz están focalizados en los negros que fueron arrancados a la fuerza de su país de origen para importarlos como esclavos en América, donde, hasta ahora practican de manera alternativa sus ritos africanos, su lenguaje, sus cantos y danzas para salvarlas del nuevo orden que representa la colonización. Algunas de estas prácticas han sido preservadas y a la vez transgredidas a tal punto que se comenzó a gestar en todo el Caribe la idiosincrasia afroamericana, producto de las mezclas y la interculturalidad. En un periodo de tiempo largo y complejo, el conjunto de creencias de diversas fuentes culturales se ha movido con fuerza, acuñando la aculturación como una especie de dominación, ejercida por quienes se suponen más educados, informados o más desarrollados, sobre otros más débiles y menos civilizados. 
Por lo tanto, aculturar significa tender a mejorar para crear otra cultura; recibir y asimilar la ayuda o los bienes aportados sin cuestionamientos. Mientras que transculturar, no sólo es adueñarse de estos beneficios, sino desterrar algunos rasgos, lo que implica desculturizar y ganar para legitimar otros valores.

Un ejemplo del proceso de transculturación en la música cubana es la mezcla de la canción del blanco con los tambores agitados de los negros. La combinación cultural y racial tan estrecha creó un campo fértil para que la música criolla creciera como algo nuevo, producto de la unión de dos legados culturales distintos. En ese apartado, Ortiz habla de lo transculturado como un tercer elemento vivo y real, resultado de la mezcolanza entre dos componentes desiguales. Este tercer elemento no genera una nueva civilización, ni un nuevo arte sino una variante compleja de la fase inicial; en este caso lo transcultural se ve como una realidad que se va gestando en un proceso integrador no formado completamente.

Para explicarlo mejor, citamos el caso del etnólogo británico Ranulph Marett conocido comúnmente como R. R. Marett, que publicó en 1920 su libro Psychology and Folklore, en él que indica que coexisten transvaloraciones verticales, identificadas como cambios de rango en las comunidades y transvaloraciones horizontales, identificadas como cambios de dirección. Como ejemplo, se pueden citar los bailes criollos en América, para el primer caso y la música religiosa mulata en el segundo. En la transculturación los traspasos se observan en cualquier sentido, tanto en las culturas inferiores como en las más adelantadas ya que se puede transculturar de igual manera, una mitología, un arma o una melodía. La idea es fundamental porque se vislumbra que el poder transculturador toca las personas, las cosas y los productos desarrollados dentro del seno social, llámese cualquier producción que refleje las condiciones del espíritu y del tiempo humanos: como el arte y el diseño.

Tanto en los procesos culturales como en el arte, trans, significa "para llegar a" término que por sí mismo sugiere un flujo de características y una transposición de elementos de un lugar a otro; la transcultura advierte al individuo la interculturalidad y en este reconocimiento, el sujeto posiciona su propio quehacer y el quehacer de los otros frente a él. Un ejemplo en el arte, es el del poeta moderno Ángel Rama, hijo de emigrantes gallegos a Uruguay, nacido en Montevideo en 1926, miembro de la generación del 45 o generación crítica, a quién se denominó también como el gran transculturador, término enmarcado en la década de los años sesenta en pleno boom literario de latinoamericanos en Europa. Rama escribió dos libros básicos en su trayectoria como agente cultural: Rubén Darío y el Modernismo de 1970, y Transculturación y Narrativa en América Latina de 1982. En el primero explora la posición del escritor dentro de los sistemas de validación y su relación con los lectores, que cansados de la producción literaria romántica de herencia europea se ciñen con fuerza al periodismo literario que promueve Rubén Darío. Es interesante pensar que para Rama existen dos ejes fundamentales: el del público como consumidor y el del escritor modernista como productor, que hace uso de los espacios culturales e históricos que tiene a su alcance para participar en la formación de públicos nacionales. Lo que dice Rama es que Rubén Darío en su búsqueda perpetua de originalidad poética logró hacer de la poesía española y francesa una transformación creadora y original para Latinoamérica y no una simple imitación.

En esa época, el auge literario y las tendencias desarrollistas dejaban relegadas a las culturas populares, no obstante Rama abrió un espacio para integrarlas a la modernidad para mostrar las tradiciones locales, traducidas a un discurso creativo capaz de resistir y enfrentarse a cualquier discurso hegemónico. En este sentido, la producción discursiva resulta tanto del genio del escritor, como de su capacidad para traducir con originalidad las formas culturales que el pueblo propone. En el libro: Rubén Darío y el Modernismo, pretendió copiar el modelo cultural y literario europeo y aplicarlo al de América Latina, más tarde se dio cuenta de la legítima y necesaria reivindicación de los caracteres indígenas, por lo tanto en Transculturación Narrativa de América Latina, aplicó al propósito modernizador europeo un discurso nacional, negándole de cierta manera a los extranjeros el proyecto único de nación, en busca primordialmente, de una reivindicación para los participantes de la transculturación regional.

Esta idea se sostiene cuando el escritor hace una crítica a los autores literarios, que con el boom editorial de los 60 que favoreció a los latinoamericanos en Europa, al ser traducidos a otros idiomas por facilidades lingüísticas o por contar con formas culturales de mayor reconocimiento como es el caso de las obras de Borges, Vargas Llosa o Julio Cortázar, reflejo una transculturación de Latinoamérica para el mundo. Mientras que figuras como Juan Rulfo, José María Arguedas, Joao Guimaraes Rosa o Augusto Roa Bastos ejemplificaron la imagen de los literatos que lograron transculturar internamente su país de origen. Este enfoque crítico y posiblemente sobrevalorado de la transculturación en aras de identificar las particularidades de las relaciones entre culturas tan diferentes, lo da como respuesta Rama en un momento clave, ante el imperialismo cultural, 
cuando los medios de comunicación masiva distorsionaban la realidad y urbanizaban al continente, dejando a la Latinoamérica rural en el olvido.

Este aspecto de la literatura latinoamericana no es diferente al de las demás artes, incluidas las plásticas y visuales y el diseño gráfico, en ellas se da actualmente la mezcla de lo indígena, lo rural, lo urbano, lo popular y lo masivo y lo culto como labor de una colectividad capaz de construir cosmovisiones, nuevos lenguajes y efectos interculturales en un proceso mediante el que siempre se da algo a cambio de lo que se recibe. En un proceso en el que las partes involucradas en los intercambios de conocimiento, resultan modificadas, resultando una nueva realidad, compuesta y compleja; una realidad que no es una simple aglomeración material de caracteres, ni un collage de acontecimientos, sino un fenómeno cultural original digno de analizar.

\section{CONCLUSIONES}

Para describir los procesos derivados de la interculturalidad como el de hibridación o el de transculturación, es necesario hacer hincapié en las situaciones particulares derivadas de los roces entre los grupos sociales que se mezclan, para llegar a establecer la superación dialéctica de las diferencias y para poder utilizarlas en estos estudios como mecanismo facilitador del entendimiento de las características propias, no de uno, sino de varios sistemas culturales y sus consecuentes relaciones. En el caso latinoamericano, los sistemas culturales se alimentan de sujetos diferenciados por su pertenencia a diferentes ámbitos lingüísticos o ideológicos y como constructores de imaginarios que frecuentemente viven en contienda.

Uno de los conflictos más evidentes al utilizar términos totalitarios para definir los procesos culturales, aún sabiendo que se trata de una serie de sucesos cambiantes y con capacidad de interactuar con promiscuidad, es el afán por presentar los procesos culturales como efectos globalizadores masivos, completos, terminados y cerrados, abarcadores e incluyentes de todas las situaciones involucradas, máxime cuando los procesos culturales por el contrario no son fenómenos cerrados sino en continua transformación. Intentar estandarizarlos puede reducirlos a prácticas totalitarias y demasiado subjetivas, por lo tanto se sugiere describir y explicar los términos derivados de las interacciones culturales para visualizar objetos de estudio específicos, que por su parte puedan ser tratados dentro del esquema móvil y nominativo del término: Procesos de transformación que pueden por demás ser aplicados empíricamente a tácticas o estrategias interculturales que pueden derivar en diversos tipos de relaciones aleatorias y azarosas.

La transculturación y las hibridaciones corresponden a procesos interculturales con particularidades visibles en continuo cambio y transformación, son el lugar desde donde pueden comenzar nuevas búsquedas interiores y exteriores para reinventar las identidades y al mismo tiempo para expandirlas hacia otros lugares. Reconocer dichos procesos le permite al arte articular posibles combinaciones para situarse en medio de la heterogeneidad del conocimiento. En este caso lo importante es que al entender las relaciones posibles, se puedan entramar muchas más, con resultados y proyecciones diversas entre los diferentes actores involucrados. Para el arte actual es muy importante lo que se quiere decir, o sea el campo de los conceptos en donde se pueden ver con más claridad los efectos de la interculturalidad. Otro apartado importante en el arte corresponde al cómo se dice y a qué clase de soportes se utilizan para ello, o sea, el espacio de lo formal, que es básicamente donde se pueden ver con más claridad las interrelaciones formales, sobre todo las que tienen que ver con las diversas posibilidades de combinación que afectan situaciones estructurales de las obras.

Derivado de ello, los procesos de transculturación y las hibridaciones, contienen bases fincadas en actitudes y referencias múltiples, variadas, movedizas y a veces contradictorias pero capaces de producir resultados evidentes en su constante movilidad. Esos procesos interculturales en las artes son el resultado de un conjunto de interacciones históricas, socio-económicas y políticas con esencias sistemáticas y recurrentes pero procesuales a la vez, ellas registran los cambios constantes que reflejan el pensamiento de cada época. Esta idea explica las influencias de lo híbrido y lo transcultural como el conjunto de actitudes y referencias de diverso tipo, ensalzadas por características culturales esenciales, interpretables y móviles pero efectivas. Las identificaciones de los procesos culturales corresponden a construcciones colectivas en las que se reflejan diversos valores materiales, espirituales, de lenguaje y de usanza cotidiana, que se articulan de manera aleatoria y azarosa. A este efecto autores como Gilles Deleuze, lo denominaron efecto rizomático, en una concepción también amplia que implica una organización que no sigue líneas de subordinación jerárquica, en la cual, de una raíz con múltiples tentáculos nacen otras series de ramificaciones que involucran el desarrollo de otras más, sujetas a posibles crecimientos y decrecimientos 
procesuales. Seguramente estas disposiciones serán el objeto de estudio de futuras investigaciones en el arte.

\section{FUENTES DE CONSULTA.}

-Beverly, John. Sobre la situación actual de los estudios culturales. José Antonio Mazzotli y Juan Cevallos: Asedios a la heterogeneidad cultural. Philadelphia: Asociación Internacional de Peruanistas, 1996.

-Deleuze, Gilles. Lógica de/ sentido, Editorial Minuit. París, Francia, 1969.

-Deleuze, G., Guattari F. Mil mesetas, capitalismo y esquizofrenia. Valencia, España. Editorial Pre-textos, 2000.

-García Canclini, Nestor. Culturas Hibridas, estrategias para entrar y salir de la modernidad. Editorial grijalbo, México, 1990.

-Kuspit, Donald. Lo contemporáneo y lo histórico más reñidos que nunca. IV Simposio Internacional sobre teoría de arte contemporáneo Enero 20 al 22. Mitos de permanencia y fugacidad. México, 2005.

Malinowski, Bronislaw: "Introducción" a Contrapunteo cubano del tabaco y del azúcar. La Habana, Cuba. Editorial de Ciencias Sociales de La Habana. 1940.

-Ortiz, Fernando. Los negros brujos, Pensamiento cubano. Editorial de ciencias sociales. La Habana Cuba, 1995.

-Said, Edward. Cultura e imperialismo. 50a ed. México, DF, Editorial Anagrama. 2001

\section{Álvaro Villalobos Herrera}

villalher@gmail.com

Doctor en Estudios Latinoamericanos y Maestro en Artes Visuales por la UNAM y la Facultad de Artes ASAB de la Universidad Distrital de Bogotá. Investigador del Sistema Nacional de Investigadores de México. Profesor de la Facultad de Artes UAEM y la Facultad de Estudios Superiores Acatlán UNAM. Publica libros y artículos regularmente y participa activamente en exposiciones, eventos teóricos y festivales de performance, con trabajos que vinculan el arte con los problemas sociales y políticos.

\section{Cynthia Ortega Salgado}

hopperonmirror@hotmail.com

Doctorante en Estudios Latinoamericanos por la UNAM y Maestra en Artes por la Universidad de Plymouth. Investigadora invitada de la Facultad de Humanidades, Universidad de la República, Montevideo. Sus artículos comprenden libros electrónicos, prensa nacional y la revista indexada del College of arts \& letters de la Universidad de California. Labora como profesora de tiempo completo perfil PROMEP, en la Facultad de Artes de la UAEM y es parte del cuerpo académico "el arte como conocimiento".

Fecha de Recepción: 20 /01/ 2012

Fecha de Aprobación: 13/03/ 2012 